Yayın Geliş Tarihi (Submitted): 27/03/2021

Yayın Kabul Tarihi (Accepted): 16/05/2021

Makele Türü (Paper Type): Araştırma Makalesi - Research Paper

Please Cite As/Atıf için:

Çetinkaya Ç. (2021), Parameter estimation for a k-unit series system based on the progressively censored erlang-truncated exponential data with binomial removals, Nicel Bilimler Dergisi, 3(1), 59-71. doi: 10.51541/nicel.904461

\title{
PARAMETER ESTIMATION FOR A $K$-UNIT SERIES SYSTEM BASED ON THE PROGRESSIVELY CENSORED ERLANG-TRUNCATED EXPONENTIAL DATA WITH BINOMIAL REMOVALS
}

\author{
Çağatay Çetinkaya ${ }^{1}$
}

\begin{abstract}
This study deals with point and interval estimations for the scale and shape parameters of the component lifetime distribution of a k-component series system when the component lifetimes are assumed to be independently and identically Erlang-truncated exponential distributions. It is assumed that the components are exposed to progressive Type-II censoring scheme. Each failure in this censoring plan is assumed to be random and subject to the binomial distribution. Parameter estimations are obtained by using the maximum likelihood method and their approximate confidence intervals are obtained by using the bootstrap method. The simulations are performed to evaluate the performances of the theoretical outcomes.
\end{abstract}

Keywords: Bootstrap, Erlang-Truncated Exponential Distribution, Maximum Likelihood, Progressive Censoring, Series system

${ }^{1}$ Sorumlu yazar,Dr. Öğr. Üyesi, Bingöl Sosyal Bilimler Meslek Yüksekokulu, Bingöl Üniversitesi, Bingöl, Türkiye, ORCID ID: https://orcid.org/0000-0001-8010-4261 


\section{BİNOM KALDIRMALAR İLE AŞAMALI SANSÜRLENMIŞ ERLANG-KESILMIŞ ÜSTEL VERILLERE DAYALI BİR K-BİRIMLİ SERİ SISTEM İÇIN PARAMETRE TAHMINI}

\section{ÖZET}

$\mathrm{Bu}$ çalışma, bileşen ömürlerinin bağımsız ve özdeş Erlang kesilmiş üstel dağılımına sahip olduğu varsayıldığında, bir k-bileşenli seri sistemin bileşen ömrü dağılımının ölçek ve şekil parametrelerinin parametre tahminlerini ele almaktadır. Bileşenlerin aşamalı Tip-II sansürleme şemasına maruz kaldığı varsayılmaktadır. Bu sansürleme planındaki her bir başarısızlığın rastgele olduğu ve binom dağılımına sahip olduğu varsayılır. Parametre tahminleri, maksimum olabilirlik yöntemi kullanılarak, yaklaşık güven aralıkları ise bootstrap yöntemi kullanılarak elde edilmiştir. Teorik sonuçların performanslarını değerlendirmek için simülasyon çalışmaları uygulanmıştır.

Anahtar Kelimeler: Bootstrap, Erlang Kesilmiş Üstel Dağılım, En Çok Olabilirlik, Aşamalı Sansürleme, Seri Sistem

\section{INTRODUCTION}

The Erlang-truncated exponential (ETE) distribution was introduced by El-Alosey (2007) as an extension of the classical exponential distribution. It is a mixture of the Erlang and the left truncated exponential distributions. Its probability density (pdf) and cumulative distribution function (cdf) are given by

$$
\begin{aligned}
& f(x \mid \lambda, \beta)=\beta\left(1-e^{-\lambda}\right) e^{-\beta\left(1-e^{-\lambda}\right) x}, \quad x>0, \lambda, \beta>0 \\
& F(x \mid \lambda, \beta)=1-e^{-\beta\left(1-e^{-\lambda}\right) x}
\end{aligned}
$$

where $\lambda$ and $\beta$ are the scale and shape parameters, respectively. The ETE distribution reduces to the one-parameter exponential distribution in the case of $\lambda \rightarrow \infty$. Recently, the ETE distribution was studied by various authors. Mohsin (2009) handled recurrence relations for single and product moments of record values. Khan et al. (2010) considered its moments of generalized order statistics and characterization. Rao (2013) handled one-sided cumulative sum 
control charts. Kulshrestha et al. (2013) studied the moment generating functions of generalized order statistics from ETE distribution. Kumar (2014a, 2014b) studied quotient moments based on records and relations of generalized order statistics. Gadde (2017) obtained reliability estimation in a multicomponent stress-strength model. Malik and Kumar (2017) considered relations for moments of progressively type-II right censored order statistics. Sarana et al. (2018) studied relationships for moments of generalized order statistics and related inference. Further, some generalizations and modifications of the ETE distribution was studied by various authors such as Nasiru et al. (2016), Okorie et al (2016, 2017a, 2017b), Jimoh et al. (2019) and Elbatal and Elgarhy (2020).

In reliability theory, many researchers are focused on the systems. Since the ETE distribution proposed a lifetime distribution, we focus on the lifetime distribution of a k-unit series system with ETE distributed lifetimes of the components.

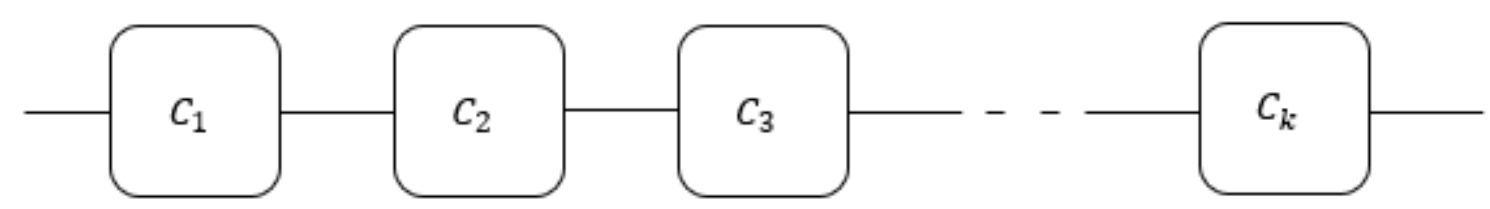

Figure 1. A configuration of the components $C_{1}, C_{2}, \cdots, C_{k}$ linked in series.

A series system functions when all the components are functioning. Thus, the structure function of a series system is given as (Smith, 2017)

$$
\emptyset\left(X_{1}, X_{2}, \cdots, X_{k}\right)=\prod_{i=1}^{k} X_{i}=\min \left(X_{1}, X_{2}, \cdots, X_{k}\right)
$$

In this study, we consider a k-unit series system with independent and identically distributed components. Let $X_{i}$ be the lifetime of the $i$ th component with $X_{i} \sim \operatorname{ETE}(\lambda, \beta)$. Let assume $X$ denotes the lifetime of a k-unit series system. Then, the system lifetime is equal to $X=\min \left(X_{1}, X_{2}, \cdots, X_{k}\right)$. The distribution and probability functions of the system lifetime can be obtained with the theory of the order statistics. That is, the lifetime of the system denotes the minimum order statistics of the components $X_{1}, X_{2}, \cdots, X_{k}$. Thus, the distribution function of $X$ is

$$
G(x \mid \lambda, \beta)=1-e^{-k \beta\left(1-e^{-\lambda}\right) x}
$$

and its pdf is 


$$
g(x \mid \lambda, \beta)=k \beta\left(1-e^{-\lambda}\right) e^{-k \beta\left(1-e^{-\lambda}\right) x}
$$

where $k=1,2, \cdots \infty$.

On the other hand, it is known that lifetimes of the components cannot be observed exactly in many cases. In the case of many reliability problem, system components can be lost or removed from the experiments before they failed and censored datasets are observed in these cases. Many different censoring schemes are defined in the literature such as Type-I censoring, Type-II censoring, hybrid censoring which is a mixture of Type-I and Type II and introduced by Epstein (1954), progressive censoring schemes which let the experimenters to remove live units on failure times. Among them, we considered the progressive Type-II censoring in this scheme. In such a censoring scheme, the experiment starts with $n$ independent and identical units which have $\operatorname{ETE}(\lambda, \beta)$. Then, the test is terminated with the prefixed $m$ th failure. When the first failure occurs $R_{1}$ live units are randomly removed from the experiment. At the second failure, $R_{2}$ live units are randomly removed from the experiment. This test terminates with $m$ th failure and the remaining surviving units $R_{m}=n-m-\sum_{i=1}^{m-1} R_{i}$ are all removed from the experiment (see Figure 2). Here $R=\left(R_{1}, R_{2}, \cdots, R_{m}\right)$ and $\sum_{i=1}^{m} R_{i}=n-m$.

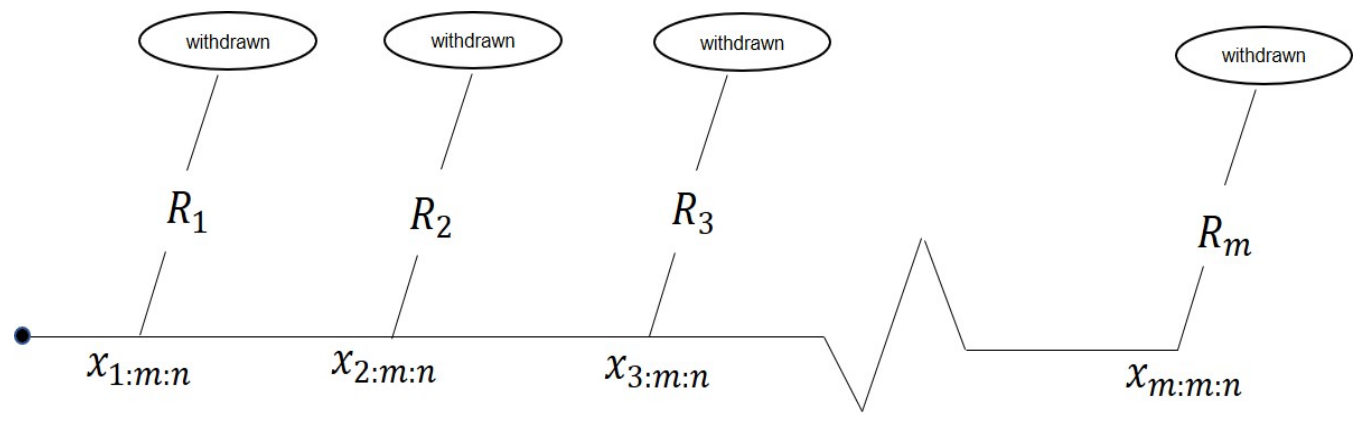

Figure 2. Structure of a progressive type-II censoring scheme

In progressive censoring schemes, the removals $R_{1}, R_{2}, \cdots, R_{m}$ are mostly predetermined before the experiment. However, in the reliability problems the amounts of units removed from the test may not always be determined exactly and these amounts can be observed as random variables. In this study, we consider the failures of the ETE components with binomial removals in a k-unit series system. For this purpose, it is assumed that the $R_{i}$ quantities which are removed randomly from the test follow the binomial distributions with probability 
$p_{i}$. That means each component has the same probability of being removed from the test as $p$. Then, the probability of units removed after the $i$ th failure time can be obtained as

$$
P\left(R_{i}=r_{i}\right)=\left(\begin{array}{c}
n-m \\
r_{i}
\end{array}\right) p_{i}^{r_{i}}\left(1-p_{i}\right)^{n-m-r_{i}}
$$

and

$$
P\left(R_{i}=r_{i} \mid R_{i-1}=r_{i-1}, \cdots, R_{1}=r_{1}\right)=\left(\begin{array}{c}
n-m-\sum_{j=1}^{i-1} r_{j} \\
r_{i}
\end{array}\right) p_{i}^{r_{i}}\left(1-p_{i}\right)^{n-m-\sum_{j=1}^{i-1} r_{j}}
$$

where $\quad 0 \leq r_{i} \leq n-m-\sum_{j=1}^{i-1} r_{j} \quad$ and $\quad i=1,2,3, \cdots, m-1$. With considering $R=R_{1}, R_{2}, \cdots, R_{m}$ and $r=r_{1}, r_{2}, \cdots, r_{m}$ we obtain

$$
\begin{aligned}
P(R=r) & =P\left(R_{m}=r_{m} \mid R_{m-1}=r_{m-1}, \cdots, R_{1}=r_{1}\right) \cdots P\left(R_{1}=r_{1}\right) \\
& =\frac{(n-m) !}{\prod_{i=1}^{m-1}\left(n-m-\sum_{j=1}^{i-1} r_{j}\right) !} p^{\sum_{i=1}^{m-1} r_{i}}(1-p)^{(m-1)(n-m)-\sum_{i=1}^{m-1}(m-i) r_{i}}
\end{aligned}
$$

In literature, there are many different studies based on progressive censoring schemes with binomial removals. For example, Weibull distributed lifetimes are considered in this plan by Tse et al. (2000). Wu and Chang (2002) handled exponential, Yan et al. (2011) generalized exponential, Mubarak (2012) Frèchet distributions in the same context.

In this study, we aimed to obtain the parameter estimations of a $k$-unit series system based on the ETE components under progressive type-II censoring scheme with binomial removals. In this purpose, we obtained the maximum likelihood estimations (MLE) of the shape and scale parameters in the Section 2. As an approximate confidence interval, we used bootstrap method in Section 3. Finally, the whole theoretical outcomes are illustrated with simulation schemes in Section 4.

\section{MAXIMUM LIKELIHOOD ESTIMATION}

We suppose that $n$ identical $k$-unit linked series units are put on life test. Let $x_{(i)}$ be the order-statistics from a progressively Type-II censored sample of size $n$ with removals $R_{1}, R_{2}, \cdots, R_{m}$ being the progressive censoring scheme. Under the assumptions of binomial removals with probability $p$, the likelihood function of the observed sample can be obtained as 


$$
\begin{aligned}
L(\lambda, \beta) & =L_{x}(\lambda, \beta) P(R=r) \\
& =C_{1} C_{2} \prod_{i=1}^{m} g\left(x_{(i)} ; \lambda, \beta\right)\left[1-G\left(x_{(i)} ; \lambda, \beta\right)\right]^{R_{i}} p^{\sum_{i=1}^{m-1} r_{i}}(1-p)^{(m-1)(n-m)-\sum_{i=1}^{m-1}(m-i) r_{i}}
\end{aligned}
$$

where $C_{1}=n\left(n-1-R_{1}\right)\left(n-1-R_{1}-R_{2}\right) \cdots\left(n-m+1-\sum_{i=1}^{m-1} R_{i}\right)$ and

$$
C_{2}=(n-m) ! / \prod_{i=1}^{m-1}\left(n-m-\sum_{j=1}^{i-1} r_{j}\right) !
$$

Thus, the likelihood function for the $k$-unit linked series ETE data is obtained as

$$
\begin{aligned}
L(\lambda, \beta) & \propto k^{m} \beta^{m}\left(1-e^{-\lambda}\right)^{m} e^{-k \beta\left(1-e^{-\lambda}\right)^{m} \sum_{i=1}^{m} x_{(i)}\left(1+R_{i}\right)} \\
& \times p^{\sum_{i=1}^{m-1} r_{i}}(1-p)^{(m-1)(n-m)-\sum_{i=1}^{m-1}(m-i) r_{i}}
\end{aligned}
$$

and the log-likelihood function is obtained as

$$
l(\lambda, \beta) \propto m\left(\log k+\log \beta+\log \left(1-e^{-\lambda}\right)\right)-k \beta\left(1-e^{-\lambda}\right) \sum_{i=1}^{m} x_{(i)}\left(1+R_{i}\right)
$$

To obtain the MLEs of the parameters, denoted by $\hat{\lambda}$ and $\hat{\beta}$, we should equate the partial derivates of $l(\lambda, \beta)$ to zero with respect to $\lambda$ and $\beta$ respectively as given in the following

$$
\begin{aligned}
& \frac{\partial l}{\partial \lambda}=\frac{m}{e^{\lambda}-1}-k \beta e^{-\lambda} \sum_{i=1}^{m} x_{(i)}\left(1+R_{i}\right)=0 \\
& \frac{\partial l}{\partial \beta}=\frac{m}{\beta}-k\left(1-e^{-\lambda}\right) \sum_{i=1}^{m} x_{(i)}\left(1+R_{i}\right)=0
\end{aligned}
$$

These non-linear equations cannot be solved analytically and iterative methods such as NewtonRaphson method are needed. Thus, approximate solutions of the system of these non-linear equations be the MLEs of the parameters.

\section{APPROXIMATE CONFIDENCE INTERVALS}

In this section, we firstly handled the asymptotic normality property of the maximum likelihood estimators to obtain approximate confidence intervals for the parameters. However, 
by performing the simulations we observed that regularity conditions for the maximum likelihood estimators cannot be satisfied in this problem. Particularly, the Fisher information matrix cannot be always obtained as a positive definite matrix in a neighborhood of the parameter space. Therefore, we considered bootstrap confidence intervals for approximate confidence intervals of $\hat{\lambda}$ and $\hat{\beta}$. The bootstrap percentile method (boot-p) is used for constructing bootstrap confidence intervals (see Efron (1994) for details).

The following steps can be used to construct a $100(1-\gamma) \%$ parametric percentile bootstrap confidence interval for one replicate.

Step 1: Draw a random sample $\left(x_{1}, x_{2}, \cdots, x_{m}\right)$ from $\operatorname{ETE}(\lambda, \beta)$.

Step 2: Compute the maximum likelihood estimates of all parameters and denote them as $\hat{\lambda}$ and $\hat{\beta}$.

Step 3: Generate independent bootstrap sample $\left(x_{1}^{*}, x_{2}^{*}, \cdots, x_{m}^{*}\right)$ from $\operatorname{ETE}(\hat{\lambda}, \hat{\beta})$ by using the inverse transformation method.

Step 4: Compute the MLEs of all parameters based on the bootstrap sample and denote them as $\hat{\lambda}^{*}$ and $\hat{\beta}^{*}$.

Step 5: Repeat step $3 B$ times to get other independent bootstrap samples from $\operatorname{ETE}(\hat{\lambda}, \hat{\beta})$ and a set of bootstrap estimates of $\lambda$ and $\beta$ and denote as $\left\{\hat{\lambda}_{i}^{*}, \hat{\beta}_{i}^{*} ; i=1,2, \cdots, B\right\}$.

Step 6: Compute $\left(\hat{\lambda}^{*(\gamma / 2)}, \hat{\lambda}^{*(1-\gamma / 2)}\right)$ and $\left(\hat{\beta}^{*(\gamma / 2)}, \hat{\beta}^{*(1-\gamma / 2)}\right)$ where $\hat{\lambda}^{*(\gamma)}$ and $\hat{\beta}^{*(\gamma)}$ are the $\gamma$-percentile of $\left\{\hat{\lambda}_{i}^{*}, \hat{\beta}_{i}^{*} ; i=1,2, \cdots, B\right\}$ that is a number such that $\frac{1}{B} \sum_{i=1}^{B} I\left(\hat{\lambda}_{i}^{*} \leq \hat{\lambda}^{*}(\gamma)\right)=\gamma$ and $\frac{1}{B} \sum_{i=1}^{B} I\left(\hat{\beta}_{i}^{*} \leq \hat{\beta}^{*(\gamma)}\right)=\gamma$ for $0<\gamma<1$.

where $I(\cdot)$ denotes the indicator function.

\section{SIMULATIONS}

In this section, we present some simulation studies to illustrate the theoretical findings. Firstly, the actual parameter values $(\lambda, \beta)$ are randomly selected as $(0.5,1.5)$ and $(1,2)$. We considered sample sizes ana corresponding failure numbers $(n, m)$ as $(20,12),(20,16)$, $(30,20),(30,25),(50,36)$ and $(50,40)$. For removal probabilities we considered three values of the binomial parameter $p$ as $0.3,0.5$ and 0.7 , respectively. We handled two different system type by taking $k=3$ and $k=6$ components. 
In order to obtain progressive censored samples from ETE distribution, we used the algorithm proposed by Balakrishnan and Sandhu (1995) as given in the following

Step 1: Generate $m$ independent $W_{1}, W_{2}, \cdots, W_{m}$ observations from $U(0,1)$.

Step 2: Set $V_{i}=W_{i}^{1 /\left(1+R_{m}+R_{m-1}+\cdots+R_{m-i+1}\right)}$ for $i=1,2, \cdots, m$

Step 3: Set $U_{i}=1-V_{m} V_{m-1} \cdots V_{m-i+1}$ for $i=1,2, \cdots, m$ as the required progressive Type-II censored sample from the $U(0,1)$.

Step 4: Set $X_{i}=F^{-1}\left(U_{i}\right)$ for $i=1,2, \cdots, m$ where $F^{-1}\left(U_{i}\right)$ is the inverse cdf of the distribution which is given in equation (3) and obtained as

$$
F^{-1}\left(U_{i}\right)=-\log \left(1-U_{i}\right) /\left[k \beta\left(1-e^{-\lambda}\right)\right] .
$$

Then, $X_{1}, X_{2}, \cdots, X_{m}$ is the required progressive Type-II censored sample from the ETE distribution.

Thus, we run the simulations for 1000 replication, and we used 500 bootstrap sample for each replicate. Then, we reported the biases, mean squared errors (MSE) and average lengths (AL) of the bootstrap confidence intervals of the MLEs of the parameters. We report the results for $(\lambda=0.5, \beta=1.5)$ in the case of $k=3$ in Table 1 and in Table 2 for $k=6$. The results for $(\lambda=1, \beta=2)$ are given in Tables 3-4 for the cases of $k=3$ and $k=6$, respectively.

Table 1. The biases and MSEs of the parameters with the corresponding ALs of their bootstrap confidence intervals for $\lambda=0.5, \beta=1.5$ and $k=3$.

\begin{tabular}{|ccccccccc|}
\hline & & & \multicolumn{6}{c}{$\hat{\lambda}$} \\
\cline { 4 - 9 }$p$ & $n$ & $m$ & Bias & MSE & $\mathrm{AL}$ & Bias & MSE & $\mathrm{AL}$ \\
\hline 0.3 & 20 & 12 & 0.06097 & 0.06940 & 0.84447 & 0.06257 & 0.00563 & 0.48692 \\
& 20 & 16 & 0.04744 & 0.04856 & 0.70748 & 0.05520 & 0.00472 & 0.40638 \\
& 30 & 20 & 0.02843 & 0.03077 & 0.64449 & 0.05105 & 0.00454 & 0.33880 \\
& 30 & 25 & 0.01690 & 0.01964 & 0.57217 & 0.04394 & 0.00459 & 0.30308 \\
& 50 & 36 & 0.00944 & 0.01385 & 0.46583 & 0.04296 & 0.00423 & 0.28017 \\
& 50 & 40 & 0.00373 & 0.01082 & 0.44077 & 0.04177 & 0.00454 & 0.27271 \\
0.5 & 20 & 12 & 0.05305 & 0.06887 & 0.83940 & 0.05718 & 0.00549 & 0.47574 \\
& 20 & 16 & 0.04390 & 0.04423 & 0.72729 & 0.05058 & 0.00434 & 0.38692 \\
& 30 & 20 & 0.02426 & 0.03107 & 0.63857 & 0.04596 & 0.00454 & 0.33622 \\
& 30 & 25 & 0.01257 & 0.01866 & 0.56463 & 0.04446 & 0.00476 & 0.30222 \\
& 50 & 36 & 0.00576 & 0.01221 & 0.46822 & 0.04449 & 0.00471 & 0.27490 \\
& 50 & 40 & 0.00117 & 0.01126 & 0.43360 & 0.04146 & 0.00446 & 0.27072 \\
0.7 & 20 & 12 & 0.05152 & 0.06754 & 0.84920 & 0.06233 & 0.00761 & 0.47314 \\
& 20 & 16 & 0.02640 & 0.04042 & 0.70939 & 0.05245 & 0.00477 & 0.37323 \\
& 30 & 20 & 0.02755 & 0.02744 & 0.63170 & 0.04892 & 0.00509 & 0.34551 \\
& 30 & 25 & 0.02712 & 0.02271 & 0.58473 & 0.04496 & 0.00491 & 0.31101 \\
& 50 & 36 & 0.00894 & 0.01339 & 0.46850 & 0.04147 & 0.00476 & 0.28031 \\
50 & 40 & 0.00240 & 0.01060 & 0.43945 & 0.03877 & 0.00454 & 0.27118 \\
\hline
\end{tabular}


We observed that the biases, MSEs and average lengths of the approximate confidence intervals decrease in parallel to increasing on sample size. There is not any important difference on the estimates depend on the number of components $(k)$. Further, the probability of removals does not have a particular effect on estimates. All the results in three cases of probabilities have similar simulation performances. Consequently, we obtained consistent results in all cases.

Table 2. The biases and MSEs of the parameters with the corresponding ALs of their bootstrap confidence intervals for $\lambda=0.5, \beta=1.5$ and $k=6$.

\begin{tabular}{|ccccccccc|}
\hline & & & \multicolumn{6}{c}{$\hat{\lambda}$} \\
\cline { 5 - 9 }$p$ & $n$ & $m$ & Bias & MSE & $\mathrm{AL}$ & Bias & MSE & $\mathrm{AL}$ \\
\hline 0.3 & 20 & 12 & 0.07030 & 0.08150 & 0.83815 & 0.06354 & 0.00606 & 0.50764 \\
& 20 & 16 & 0.04234 & 0.04586 & 0.72219 & 0.05469 & 0.00510 & 0.39249 \\
& 30 & 20 & 0.02869 & 0.02841 & 0.64501 & 0.05062 & 0.00468 & 0.34083 \\
& 30 & 25 & 0.01300 & 0.01976 & 0.56148 & 0.04337 & 0.00440 & 0.30330 \\
& 50 & 36 & 0.00516 & 0.01169 & 0.46611 & 0.04578 & 0.00465 & 0.27590 \\
& 50 & 40 & 0.00474 & 0.01253 & 0.43711 & 0.04182 & 0.00459 & 0.27523 \\
0.5 & 20 & 12 & 0.06024 & 0.06522 & 0.85010 & 0.05954 & 0.00615 & 0.48695 \\
& 20 & 16 & 0.03810 & 0.04188 & 0.71511 & 0.05260 & 0.00442 & 0.39463 \\
& 30 & 20 & 0.02754 & 0.03160 & 0.63684 & 0.05198 & 0.00461 & 0.34509 \\
& 30 & 25 & 0.02109 & 0.02156 & 0.58106 & 0.04435 & 0.00448 & 0.30417 \\
& 50 & 36 & 0.00014 & 0.01243 & 0.46125 & 0.04449 & 0.00438 & 0.27514 \\
50 & 40 & 0.00746 & 0.01235 & 0.44253 & 0.04119 & 0.00409 & 0.27586 \\
0.7 & 20 & 12 & 0.05720 & 0.07554 & 0.84534 & 0.05960 & 0.00632 & 0.47743 \\
& 20 & 16 & 0.04914 & 0.04955 & 0.72545 & 0.05357 & 0.00496 & 0.39973 \\
& 30 & 20 & 0.01967 & 0.02756 & 0.63881 & 0.05139 & 0.00447 & 0.33068 \\
30 & 25 & 0.01625 & 0.02352 & 0.56296 & 0.04805 & 0.00447 & 0.31099 \\
50 & 36 & 0.00385 & 0.01171 & 0.46686 & 0.04487 & 0.00449 & 0.27583 \\
50 & 40 & 0.00869 & 0.01078 & 0.44548 & 0.03858 & 0.00476 & 0.27243 \\
\hline
\end{tabular}


Table 3. The biases and MSEs of the parameters with the corresponding ALs of their bootstrap confidence intervals for $\lambda=1, \beta=2$ and $k=3$.

\begin{tabular}{|ccccccccc|}
\hline & & & \multicolumn{6}{c}{$\hat{\lambda}$} \\
\cline { 4 - 8 }$p$ & $n$ & $m$ & Bias & MSE & $\mathrm{AL}$ & Bias & MSE & $\mathrm{AL}$ \\
\hline 0.3 & 20 & 12 & 0.01727 & 0.14345 & 1.00151 & 0.20391 & 0.06430 & 1.55047 \\
& 20 & 16 & 0.00760 & 0.12160 & 0.90089 & 0.17249 & 0.04474 & 1.26196 \\
& 30 & 20 & 0.01283 & 0.09564 & 0.83383 & 0.15410 & 0.02569 & 1.12320 \\
& 30 & 25 & 0.01331 & 0.08726 & 0.77273 & 0.14315 & 0.02101 & 0.95903 \\
& 50 & 36 & 0.01619 & 0.07471 & 0.70575 & 0.11857 & 0.01614 & 0.78106 \\
& 50 & 40 & 0.03218 & 0.06752 & 0.68455 & 0.11654 & 0.01190 & 0.73962 \\
0.5 & 20 & 12 & 0.03521 & 0.14584 & 1.00377 & 0.21151 & 0.07450 & 1.59286 \\
& 20 & 16 & 0.00185 & 0.12563 & 0.89244 & 0.18014 & 0.04656 & 1.25016 \\
& 30 & 20 & 0.01092 & 0.10407 & 0.81456 & 0.15482 & 0.03225 & 1.12985 \\
& 30 & 25 & 0.00382 & 0.09400 & 0.75545 & 0.14648 & 0.02628 & 0.98921 \\
& 50 & 36 & 0.00479 & 0.07316 & 0.68935 & 0.11427 & 0.01536 & 0.82130 \\
50 & 40 & 0.02208 & 0.06503 & 0.68145 & 0.10944 & 0.01297 & 0.75505 \\
0.7 & 20 & 12 & 0.03761 & 0.15484 & 0.98146 & 0.21400 & 0.07623 & 1.62090 \\
& 20 & 16 & 0.02614 & 0.12077 & 0.89880 & 0.17864 & 0.04285 & 1.29916 \\
& 30 & 20 & 0.00227 & 0.10221 & 0.81540 & 0.15043 & 0.02725 & 1.12054 \\
30 & 25 & 0.00164 & 0.08828 & 0.76343 & 0.13621 & 0.02279 & 0.98271 \\
50 & 36 & 0.01549 & 0.07078 & 0.69996 & 0.12125 & 0.01628 & 0.79451 \\
50 & 40 & 0.00308 & 0.06747 & 0.67549 & 0.10821 & 0.01355 & 0.78754 \\
\hline
\end{tabular}

Table 4. The biases and MSEs of the parameters with the corresponding ALs of their bootstrap confidence intervals for $\lambda=1, \beta=2$ and $k=6$.

\begin{tabular}{|ccccccccc|}
\hline & & \multicolumn{6}{c}{$\hat{\lambda}$} \\
\cline { 4 - 9 }$p$ & $n$ & $m$ & Bias & MSE & $\mathrm{AL}$ & Bias & MSE & $\mathrm{AL}$ \\
\hline 0.3 & 20 & 12 & 0.04035 & 0.15425 & 0.99655 & 0.21166 & 0.08066 & 1.58733 \\
& 20 & 16 & 0.02112 & 0.12347 & 0.88820 & 0.17598 & 0.04283 & 1.29655 \\
& 30 & 20 & 0.01423 & 0.10455 & 0.82374 & 0.15706 & 0.03097 & 1.12677 \\
& 30 & 25 & 0.00953 & 0.09017 & 0.76600 & 0.13271 & 0.02073 & 0.97943 \\
& 50 & 36 & 0.00581 & 0.07264 & 0.69369 & 0.11653 & 0.01341 & 0.81110 \\
& 50 & 40 & 0.01761 & 0.06868 & 0.68364 & 0.11309 & 0.01386 & 0.75519 \\
0.5 & 20 & 12 & 0.01738 & 0.11963 & 0.89555 & 0.17869 & 0.04469 & 1.28519 \\
& 20 & 16 & 0.00730 & 0.11728 & 0.90559 & 0.17456 & 0.04480 & 1.26237 \\
& 30 & 20 & 0.00948 & 0.10377 & 0.82158 & 0.15060 & 0.02636 & 1.09565 \\
& 30 & 25 & 0.00093 & 0.09112 & 0.76493 & 0.14171 & 0.02346 & 0.97332 \\
& 50 & 36 & 0.00558 & 0.07241 & 0.69744 & 0.11780 & 0.01462 & 0.80725 \\
& 50 & 40 & 0.01564 & 0.06758 & 0.66947 & 0.11532 & 0.01337 & 0.77856 \\
0.7 & 20 & 12 & 0.02181 & 0.14438 & 0.99082 & 0.20551 & 0.06194 & 1.56433 \\
& 20 & 16 & 0.00548 & 0.12176 & 0.88975 & 0.17694 & 0.04447 & 1.28427 \\
& 30 & 20 & 0.01437 & 0.10081 & 0.80788 & 0.15438 & 0.02974 & 1.15162 \\
& 30 & 25 & 0.00477 & 0.09139 & 0.75898 & 0.13893 & 0.02136 & 0.97482 \\
50 & 36 & 0.02201 & 0.06699 & 0.71090 & 0.11792 & 0.01401 & 0.78432 \\
50 & 40 & 0.00777 & 0.06801 & 0.67141 & 0.11158 & 0.01406 & 0.78040 \\
\hline
\end{tabular}




\section{CONCLUSION}

In this study, a k-unit series system with Erlang-truncated exponential components is handled under a progressive censoring scheme. We considered removals in progressive censoring under the binomial distribution. It is seen that the maximum likelihood estimations and approximate confidence intervals perform well. Further, we considered asymptotic confidence intervals for the maximum likelihood estimators but regularity conditions were not satisfied always. For this reason, we discarded the asymptotic method and preferred the bootstrap method. As a result, the ETE distribution can be used for such a system under different progressive censoring schemes and parameter estimation can be obtained by using these theoretical findings.

\section{ETHICAL DECLARATION}

In the writing process of the study titled "Parameter Estimation for k-unit series system basedon the progressively censored erlang-truncated exponential data with binomial removals", there were followed the scientific, ethical and the citation rules; was not made any falsification on the collected data and this study was not sent to any other academic media for evaluation.

\section{ACKNOWLEDGEMENT}

The author would like to thank the anonymous reviewers for their valuable comments and suggestions which were helpful in improving the paper.

\section{REFERENCES}

Balakrishnan, N. and Sandhu, R. A. (1995), A simple simulational algorithm for generating progressive Type-II censored samples, The American Statistician, 49(2), 229-230.

El-Alosey, A. R. (2007), Random sum of new type of mixture of distribution, International Journal of Statistics and Systems, 2(1), 49-57.

Elbatal, I. and Elgarhy, M. (2020), A new generalization of erlang-truncated exponential distribution: properties and applications. Advances and Applications in Statistics, 64(1), 63-74.

Efron, B. and Tibshirani, R. J. (1994), An introduction to the bootstrap, CRC press. 
Epstein, B. (1954), Truncated life tests in the exponential case, The Annals of Mathematical Statistics, 555-564.

Gadde, S. R. (2017), Reliability estimation in multicomponent stress-strength based on Erlangtruncated exponential distribution. International Journal of Quality \& Reliability Management.

Jimoh, H., Oluyede, B. O., Wanduku, D. and Makubate, B. (2019), The gamma log-logistic Erlang truncated exponential distribution with applications, Afrika Statistika, 14(4), 2141-2164.

Khan, R. U., Kumar, D. and Athar, H. (2010), Moments of generalized order statistics from Erlang-truncated exponential distribution and its characterization, International Journal of Statistics and System, 5(4), 455-464.

Kulshrestha, A., Khan, R. U. and Kumar, D. (2013), On moment generating functions of generalized order statistics from Erlang-truncated exponential distribution, Open J. Statist, 2, 557-564.

Kumar, D. (2014a), Quotient Moments of the Erlang-truncated Exponential Distribution Based on Record Values and a Characterization. Journal of applied mathematics \& informatics, 32(1_2), 7-16.

Kumar, D. (2014b), Relations of generalized order statistics from Erlang-Truncated exponential distribution, Pacific Journal of Applied Mathematics, 6(1), 53.

Malik, M. R. and Kumar, D. (2017), Relations for moments of progressively type-II Right censored order statistics from Erlang-truncated exponential distribution, Statistics, 651.

Mohsin, M. (2009), Recurrence relation for single and product moments of record values from Erlang-truncated exponential distribution, World Applied Science Journal, 6(2), 279282.

Mubarak, M. (2012), Parameter estimation based on the Frechet progressive type II censored data with binomial removals, Journal of Quality and Reliability Engineering, 2012.

Nasiru, S., Luguterah, A. and Iddrisu, M. M. (2016), Generalized Erlang-truncated exponential distribution. 
Okorie, I. E., Akpanta, A. C., Ohakwe, J. and Chikezie, D. C. (2017a), The Extended ErlangTruncated Exponential distribution: Properties and application to rainfall data, Heliyon, 3(6), e00296.

Okorie, I. E., Akpanta, A. C. and Ohakwe, J. (2017b), Marshall-Olkin generalized Erlangtruncated exponential distribution: Properties and applications, Cogent Mathematics \& Statistics, 4(1), 1285093.

Okorie, I. E., Akpanta, A. C. and Ohakwe, J. (2016), Transmuted Erlang-truncated exponential distribution. Stochastics and Quality Control, 31(2), 71-84.

Rao, G. S. (2013), One-sided cumulative sum (CUSUM) control charts for the Erlang-truncated exponential distribution, Computational Methods in Science and Technology, 19(4), 229-234.

Sarana, J., Vermaa, K. and Pushkarnaa, N. (2018), Relationships for moments of generalized order statistics from Erlang-truncated exponential distribution and related inference. In ProbStat Forum (11), 91-103.

Smith, P. J. (2017), Analysis of failure and survival data. CRC Press.

Tse, S. K., Yang, C. and Yuen, H. K. (2000), Statistical analysis of Weibull distributed lifetime data under Type II progressive censoring with binomial removals. Journal of Applied Statistics, 27(8), 1033-1043.

Yan, W., Shi, Y., Song, B. and Mao, Z. (2011), Statistical analysis of generalized exponential distribution under progressive censoring with binomial removals, Journal of Systems Engineering and Electronics, 22(4), 707-714.

Wu, S. J. and Chang, C. T. (2002). Parameter estimations based on exponential progressive type II censored data with binomial removals. International journal of information and management sciences, 13(3), 37-46. 